Rose, J., \& Colman, A. M. (2007). Collective preferences in strategic decisions. Psychological Reports, 101, 803815 .

\title{
COLLECTIVE PREFERENCES IN STRATEGIC DECISIONS ${ }^{1,2}$ JO ROSE University of Exeter ANDREW M. COLMAN University of Leicester
}

\begin{abstract}
${ }^{1}$ Acknowledgements. - The authors are grateful to Marco Perugini for helpful suggestions in the planning stages of this research, and to Daniel Zizzo and other members of the Oxford Experimental Economics workshop for comments on an earlier version. The writing of this article was facilitated by Grant No. RES-000-23-0154 to the second author and a postgraduate studentship No. R00-429-834-60 to the first author, both awarded by the Economic and Social Research Council of the UK, and study leave awarded by the University of Leicester to the second author.
\end{abstract}

${ }^{2}$ Address correspondence to Dr Jo Rose, School of Education and Lifelong Learning, University of Exeter, Exeter EX1 2LU, United Kingdom, or e-mail (J.R.Rose@exeter.ac.uk).

Summary.- - In the theories of team reasoning of Sugden, and Bacharach, players are assumed to be motivated in some circumstances to maximize collective rather than individual utilities. An experiment was performed to asses whether preferences underlying such collective payoff maximization occur. An opportunistic sample of 50 undergraduate and graduate students, 7 men and 43 women aged 19 to 42 years $(M=23.0, S D=5.4)$, expressed preferences among the outcomes of strategic decisions presented in vignettes designed to engage social value orientations of individualism, altruism, competitiveness, equality seeking, or collective preferences. In the vignettes designed to engage collective preferences, and significantly less frequently in the other vignettes, preferences were biased toward outcomes maximizing collective payoffs, and respondents invariably gave team-reasoning explanations for their preferences. These results provide evidence for collective preferences according to theories of team reasoning and empirical support for one of the essential assumptions of these theories.

Both orthodox decision theory, based on subjective expected utility theory (Savage, 1954/1972), and game theory rest on a fundamental assumption of methodological individualism, according to which decision makers or players seek to maximize their individual utilities or expected utilities. Thus, for example, Jeffrey (1983) analyzed the logic of decisionmaking within a framework in which agents deliberate about the consequences of their actions according to how desirable those consequences are for themselves as individuals, exclusively. Dawes (1988) discussed rational choice in terms of the best interests "of the person making the decision" (p. 8, italics in original). Bell, Raiffa, and Tversky (1988), outlined the basic normative generalization of decision-making "that posits utility maximization behavior on the parts of individual agents [such that] each agent seeks to maximize his own expected utility given some notional expectations of what others might do" (p. 14).

A sustained program of research in the field of behavioral decision-making has shown that the bounded rationality of human decision makers causes them, in all but the simplest decisions, to use a variety of heuristics that lead to deviations from perfect utility maximizationdeviations from decisions that correspond to the decision-maker's preferences - and, in certain circumstances, to systematic biases (Kahneman \& Tversky, 1984, 2000). This article focuses on 
a more fundamental departure from the standard assumption of individual utility maximization. In some strategic decisions, there are reasons to believe that human decision makers do not merely fail to choose optimally according to their individual preferences but may adopt a different approach altogether, by seeking to maximize collective rather than individual utilities (Gilbert, 1989, 1994, 2000; Hurley, 1989, 1991, 1994; Sugden, 1993, 2000, 2005; Bacharach, 1999, 2006). Most versions of decision theory assume not only that agents have selfish preferences, invariably preferring outcomes that maximize their individual utilities, but also that they necessarily act individualistically in pursuing those preferences, rather than jointly or collectively in pursuing group goals. However, there are grounds for believing that these assumptions about selfishness and individualism may not apply universally to human preferences and decisions.

One of the grounds for skepticism is that the assumptions appear to be contradicted by intuition and experience. Taking the assumption about selfish preferences first, a woman who gives up a rewarding and enjoyable job because she wishes to care for her dying mother would not normally be characterized as seeking to maximize her individual self-interest. Actions that appear selfless can, of course, conceal hidden selfish motives, such as a desire for a "warm glow" (Andreoni, 1990), an increase in social prestige (Olson, 1965), avoidance of scorn (Becker, 1974), or alleviation of personal sadness through empathy with a grateful recipient (Cialdini, Schaller, Houlihan, Arps, Fultz, J., \& Beaman, 1987). Seemingly altruistic, principled, or public-spirited actions may in fact serve egoistic goals (Batson, 1994). It is even possible to argue that there must necessarily be a hidden selfish or egoistic motive behind every apparently selfless action, otherwise the action would not be performed, but this involves a conception of human motivation that is either tautological, if voluntary behavior is assumed to be selfish by definition, or else empirically false, because prima facie instances of nonselfish behavior are not difficult to find in everyday life.

Consider the individualistic assumption, applied to the motivation of the woman in the above example and whether or not it is based on selfish preferences. Her motivation is clearly individualistic in the sense of its being her personal wish to care for her mother. However, in certain strategic decisions, the reasoning from preferences to actions or decisions may be nonindividualistic in the sense that individual preferences may play no part in it. The following hypothetical example illustrates this. There is a plan to close an adventure playground for children in my village; I have no children, but I and the other people who live in the village all want to keep the playground; The authorities will relent if and only if everyone in the village objects in writing; Therefore, I should write to the authorities objecting to the plan.

This is an example of team reasoning. It is inherently collectivistic and does not presuppose any hidden individualistic premise (Gilbert, 1989, 1994). From a premise of the general form We desire $x$, whatever $x$ might be, plus specific premises about the appropriate means to achieve $x$, "a conclusion about what an individual should do can follow directly, without the interposition of any assumptions about what that individual wants or seeks. Indeed, no single individual's aims need be referred to" (Gilbert, 1989, p. 708, italics in original). In team reasoning, decision makers do not focus on their individual goals, whether those goals are selfish or altruistic, but on the decision makers' roles in achieving a group goal.

Sugden (1993) described team reasoning as "a theory in which individuals can act cooperatively, following rules which it would be in everyone's interest for everyone to follow" (p. 89). Referring to essentially the same phenomenon, Gilbert (1994) wrote that "one acts from groupish motives when one acts so as to promote what one perceives as 'our' goals, needs, and 
so on" (p. 621, italics in original). Team reasoning entails being motivated by group preferences and reasoning in a distinctive way from preferences to actions. A team-reasoning agent first computes a profile of strategies that maximizes the objective function of the group as a whole, then, if this profile is unique in the sense that no other combination of strategies maximizes the objective function, chooses the strategy that is a component of it and acts accordingly. Orthodox decision theory (e.g., Savage, 1954/1972, and virtually all subsequent decision theories) is restricted to a special case in which the group is a singleton (one-person group). Bacharach (1999) characterized a team-reasoning agent as someone who "chooses the act (if this is unique) which is her component in the profile which is best for the objective of some group" (p. 132, italics in original). In formal theories of team reasoning (Sugden, 1993, 2005; Bacharach, 1999, 2006), there is an assumption that agents are free to choose for the group or for themselves as individuals, depending on circumstances.

A prerequisite for team reasoning is an inherent motivation to aim for the best group outcome and to adopt the group's preferences as a guide to action. The purpose of the experiment described below is to seek direct empirical evidence for the existence of collective preferences, of the type implied by Sugden $(1993,2005)$ and Bacharach $(1999,2006)$. Without collective preferences, there can be no team reasoning. Collective preferences are a necessary but not a sufficient condition for team reasoning because, for team reasoning to occur, decision makers not only prefer the collectively optimal outcome but also reason from preferences to actions in a way that is quite distinct from other forms of decision theory. The general methodology involved devising simple and transparent decision scenarios, presented in the form of vignettes describing dyadic strategic decisions, in which collective preferences - preferences for collective utility maximization - could be distinguished empirically from preferences associated with social value orientations of individualism, altruism, competitiveness, and equality-seeking. The team-preference vignettes were designed to engage collective preferences distinct from individualistic preferences, and the other vignettes were designed to engage preferences associated with other social value orientations.

In each vignette, response alternatives were designed to be mutually exclusive in the sense, for example, that an alternative maximizing individual payoff, and hence reflecting the individualistic social value orientation, did not maximize the variable reflecting any of the other social value orientations (McClintock, 1972; Van Lange, 1999), namely the other's payoff (altruism), the difference between own and other's payoff (competitiveness), equality of payoffs (equality seeking), or joint payoff (collective payoff maximization). In the same way, each of the other response alternatives invariably reflected one and only one of the social value orientations listed above. The vignettes provided a deliberately simplified context in which to examine preferences, without the complications arising in project teams with interacting members (e.g., Miles, 2000; Fontaine, 2004; Forester, Thoms, \& Pinto, 2007). An example of a vignette used in the experiment is given in the Method section below.

The experimental hypotheses were that participants' preferences would be significantly biased toward collective payoff maximization in vignettes designed to engage team reasoning and that, in those vignettes, the participants' reasons for their preferences, elicited by a questionnaire, would reflect team reasoning. 


\section{Participants}

\section{METHOD}

An opportunistic sample of 50 undergraduate and graduate psychology students, 7 men and 43 women, with ages ranging from 19 to 42 years $(M=23.0, S D=5.4)$, were recruited as volunteer participants for the experiment, which was presented to them as a study of decisionmaking. No remuneration or course credits were offered.

\section{Materials and Procedure}

Data were collected through a 10-part questionnaire, comprising two vignettes representing each of five different types of decision scenarios. Each type differed from the others in the social value orientation that it was designed to engage, and the order of the vignettes was varied randomly across questionnaires.

For simplicity, each vignette described a two-person decision scenario, a dyad being the smallest group in which collective preferences are possible. Each vignette was designed, on intuitive and common-sense grounds summarized below, to engage either team reasoning or a standard social value orientation. Thus, each of the following social value orientations was represented by two vignettes in the questionnaire, individualism, altruism, competitiveness, equality seeking, and team reasoning. Individualism was defined as maximizing own payoff, and is expected in situations in which, for practical or conventional reasons, one's individual payoffs and those of the coplayer could not or would not be redistributed or shared. Altruism was defined as maximizing the other's payoff, and is expected in situations in which one has a close relationship with a coplayer whose need is greater than one's own. Competitiveness was defined as maximizing one's own minus the other's payoff, and is expected in situations such as recreational games or business interactions in which cultural norms prescribe or encourage competitiveness. Equality seeking was defined as minimizing the absolute difference between own and other's payoff, expected in situations in which moral or ethical considerations of fairness prescribe or encourage equal payoffs to both players. Collective preferences were defined as playing one's part in an outcome maximizing the dyad's collective payoff, expected in situations in which payoffs go into a common pool and the players benefit jointly from the cooperative outcome.

As an example, one of the two individualistic vignettes used in the experiment was as follows: "You and a classmate have completed an on-line test for potential employers to assess your computing abilities, the results of which would be a useful addition to your CV. Scores for the test are out of 100. Which of the following would you prefer?" This was followed by five response alternatives defined by pairs of payoffs labeled "you score (classmate scores)." In this vignette, the five response alternatives were: 65 points (95 points), 80 points (50 points), 65 points (10 points), 30 points (100 points), and 65 points (60 points). The first of these options uniquely maximizes the collective payoff inasmuch as there is no other option in which the sum of the two payoffs is as high (collective preferences); the second, individual payoff, because no other option yields as much to the self (individualism); the third, own minus other's payoff, because no other option yields a larges difference between own ant other's payoff (competitiveness); the fourth, other's payoff, because no other option pays the other as much (altruism); and the fifth, equality of payoffs, because no other option makes own and other's payoff as close to each other (equality seeking). Thus, each response alternative uniquely optimizes one and only one social value orientation. In spaces provided on the answer sheet, 
respondents were requested to "Please tick your preferred outcome (one only)" and "Please give a brief reason below for your choice."

The other individualistic vignette described a scenario in which the respondent and a nextdoor neighbor win different amounts of money in a prize draw. One of the altruistic vignettes described the respondent's best friend's flat being burglarized and then both individuals winning different amounts of money in a game of bingo; the other described the respondent's sister being given six months left to live and both individuals then winning different amounts of money in a lottery. One of the competitive vignettes described the respondent and another person setting up hot dog stands and attracting different numbers of customers; the other described the respondent and a drinking acquaintance playing pool and winning different numbers of games. One of the equality-seeking vignettes described the respondent and a friend helping a mutual acquaintance collect and chop wood for the winter and being paid different amounts of money for the work; the other described the respondent and a brother being left different amounts of money in a family friend's will. Collective preferences were represented by two vignettes: the first described the respondent and another person being involved in a campaign against a test site for genetically engineered (GM) crops and collecting different numbers of names for a petition; the other described the respondent and a friend raising different amounts of money through sponsored head shaves for new computers in their school. In each vignette, the five specified payoffs, assumed to represent the relevant utilities of the players, represented the five social value orientations outlined above. However, actual amounts of the payoffs varied across vignettes.

To summarize, participants were presented with a booklet containing the 10 vignettes, arranged in different orders for different participants, each vignette being followed by a set of five response categories. Each response category showed a different pair of payoffs for the respondent and the other person in the vignette, and respondents were asked to tick their most preferred outcomes and briefly explain their reason for their preferences. In each case, the five response alternatives uniquely reflected individualism, altruism, competitiveness, equality seeking, and collective payoff maximization, respectively. The questionnaire took about 15 minutes to complete.

\section{Scoring}

For each vignette, the frequency distribution of preferences across alternatives was noted, and chi-square goodness-of-fit tests were performed to determine whether the observed distributions of preferences deviated significantly from chance. For example, for each of the two individualistic vignettes, the relative frequencies of individualistic versus nonindividualistic preferences (altruistic, competitive, equality-seeking, or collective preferences) were tested against the chance distribution of 20 percent versus 80 percent, and the corresponding test was performed with appropriate changes for each of the other vignettes.

In cases in which the collective preference option was chosen, the participants' stated reasons for their preferences were classified into categories by the two authors. The categories were formed on the basis of a qualitative analysis in which responses turned out to fall naturally into a small number of easily recognizable categories corresponding roughly, but not completely, to the basic social value orientations built into the experiment. 
Preferences

\section{RESULTS}

The frequencies of individualistic, altruistic, competitive, equality-seeking, and collective utility maximizing in the ten vignettes are shown in Table 1. In most of the vignettes, preferences were significantly biased in the direction of the response alternative that the vignette was designed to engage (shown in parentheses beside the name of each vignette). In one of the altruistic vignettes and both of the competitive vignettes, preferences did not deviate significantly from chance. However, in both of the collective preference vignettes, preferences were strongly and significantly biased in the direction of the collective preferences option, and this is consistent with the first experimental hypothesis.

TABLE 1

FREQUENCIES OF INDIVIDUALISTIC (I), ALTRUISTIC (A), COMPETITIVE (C), EQUALITY-SEEKING (E), AND COLLECTIVE (T) PREFERENCES IN TEN EXPERIMENTAL VIGNETTES $(\mathrm{N}=50)$

\begin{tabular}{lrrrrrr}
\hline & \multicolumn{7}{c}{ Preference frequencies } & \multirow{2}{*}{$\chi^{2}$} \\
Vignette & A & C & E & I & \multicolumn{1}{c}{ T } & \\
\hline Computer test (I) & - & - & 8 & 42 & - & $128.00^{*}$ \\
Prize draw (I) & 1 & 1 & 9 & 37 & 2 & $91.12^{*}$ \\
Burglary (A) & 40 & - & 2 & - & 8 & $112.50^{*}$ \\
Lottery (A) & 15 & 2 & 14 & 2 & 17 & 3.13 \\
Hot dog (C) & 1 & 5 & 12 & 30 & 2 & 3.13 \\
Pool game (C) & - & 7 & 15 & 28 & - & 1.13 \\
Firewood (E) & - & - & 40 & 4 & 6 & $112.50^{*}$ \\
Will (E) & - & - & 47 & 1 & 2 & $171.13^{*}$ \\
GM site (T) & 1 & - & 7 & - & 40 & $128.00^{*}$ \\
Sponsorship (T) & 1 & - & 8 & 11 & 30 & $50.00^{*}$ \\
\hline
\end{tabular}

$* p<.001$, two-tailed

\section{Qualitative Results}

The reasons given by participants for collective preferences were found by the raters to fall naturally and usually unambiguously into the following categories. Team reasoning $(\mathrm{T})$ aims for the highest collective payoff for the pair. For example, in the petition vignette, one respondent wrote: "As collectively we'd have the most names." Altruistic reasoning (A) aims for the highest overall payoff for the coplayer. For example, in the vignette describing the dying sister: "These two amounts make the most money which may help my sister to do as much as she wants before she dies." Best-for-both reasoning (B) aims for a high individual payoff for each participant. For example, in the burglary vignette: "The most I can get here is $£ 80$, but if I get $£ 80$ she only gets $£ 45$. I might feel sorry in some way to have won so much more than her. The next highest amount that I can get is $£ 65$. So if I have a maximum of $£ 65$ and I can chose what she gets here, I might as well maximize it. She has had bad luck after all. $£ 65$ is good winnings for me, and I would be happy for her to win $£ 85$ in this scenario." Pacifying the coplayer (P) aims to placate the coplayer. For example, in the burglary vignette: "It might stop them moaning." The final category was used when no (intelligible) reason was given $(\mathrm{O})$. 
TABLE 2

FREQUENCIES OF REASONS FOR COLLECTIVE PREFERENCES IN TEN EXPERIMENTAL VIGNETTES: TEAM REASONING (T), ALTRUISTIC (A), BEST-FORBOTH (B), AND PACIFYING (P), (O = NO REASON GIVEN)

\begin{tabular}{lcccccc}
\hline & & \multicolumn{6}{c}{ Reasons for collective preferences } \\
\cline { 3 - 7 } Vignette & Collective prefs. & T & A & B & P & O \\
\hline Computer test (I) & 0 & - & - & - & - & - \\
Prize draw (I) & 1 & 1 & - & - & - & - \\
Burglary (A) & 9 & 1 & 1 & 5 & 1 & 1 \\
Lottery (A) & 17 & 4 & 5 & 7 & 1 & - \\
Hot dog (C) & 2 & 2 & - & - & - & - \\
Pool game (C) & 0 & - & - & - & - & - \\
Firewood (E) & 6 & 6 & - & - & - & - \\
Will (E) & 2 & 2 & - & - & - & - \\
GM site (T) & $42^{*}$ & 42 & - & - & - & - \\
Sponsorship (T) & $30^{*}$ & 30 & - & - & - & - \\
\hline \multicolumn{2}{l}{}
\end{tabular}

Note. Team-preference vignettes are indicated by $(\mathrm{T})$.

$* p<.001$, one-tailed.

Table 2 shows the frequencies with which each of the above reasons were given for collective preferences in the ten vignettes, including collective preferences in vignettes designed to engage other social value orientations. Once the raters had agreed on the categorization of reasons, the classification was obvious in the great majority of cases, and the interrater agreement was virtually perfect (almost 1.0). These data strongly corroborate the second hypothesis, inasmuch as team-reasoning explanations were invariably given for preferences in the two vignettes designed to engage collective preferences, namely the GM site and sponsorship vignettes, and this bias was statistically significant in both cases. It is worth commenting that the only vignettes in which collective preferences were ever expressed for nonteam-reasoning reasons were in the two vignettes designed to engage altruistic orientations.

Reasons for other preferences showed further patterns. Of those who preferred the equalityseeking payoffs, explanations in the equality-seeking vignettes tended to focus on fairness of payoffs, for example in the firewood vignette: "It seems like we'd both deserve the same," and avoiding bad feeling or arguments, for example in the will vignette: "Then, neither would feel jealous or guilty" (this reason was especially common in the will vignette). However, across all ten vignettes, a minority of participants commented on a general preference for equality, for example, in the will vignette: "Simply because I would want it shared equally." This seems to be a generic preference that is not context-dependent, unlike many of the other reasons expressed by respondents. The most common reason given for an individualistic preference was standard individualistic reasoning, for example, in the prize draw vignette: "Because that's the maximum amount I can win." However, another common reason given for individualistic preference, particularly in the competitive vignettes, was restrained competition, for example, in the pool game vignette: "I win, which is good, but it is reasonably equal, so the games would be more 'fun'," and in the hotdog stall vignette: "Once again, I suppose I am a bit competitive, so I'd like to get more custom than my rival." Altruistic preferences occurred mainly in the vignettes designed to engage altruism, and reasons given were mainly altruistic, for example, in the burglary vignette: “That's the most my friend could win and considering the bad luck they'd had 
they'd deserve something." Few participants showed competitive preferences, but when they were cited, the reasons given were also largely competitive, for example, in the hotdog stall vignette: "I make much more profit this way than the other stall."

\section{DISCUSSION}

The results shown in Table 1 provide clear evidence that preferences were significantly biased toward collective payoff maximization in both of the vignettes designed to engage collective preferences, and this corroborates the first hypothesis and furnishes empirical evidence for collective preferences. The second hypothesis, that team-reasoning explanations would be given for collective preferences in the vignettes designed to engage collective preferences, was corroborated without any exceptions, as shown in Table 2 . Taken together, these results are consistent with the existence of collective preferences of the type assumed by theories of team reasoning to occur in strategic decisions with appropriate characteristics.

The framing of the payoffs was clearly crucial in determining preferences for different outcomes. The presentation of a decision problem can affect the way a person interprets and responds to it (Tversky \& Khaneman, 1981), and the interpretive frame of a problem can affect strategies that decision makers use (Ormerod, Manktelow, Robson, \& Steward, 1986; Bacharach, 1994) and the decisions that they make (for example, Eiser \& Bhavnani, 1974; Tversky \& Khaneman,; Levin \& Gaeth, 1988; Manktelow \& Over, 1991), even if the structure of the problem remains unchanged. In our study, the reasons that participants gave for their preferences often indicated conscious considerations of the context or frame, although some of their reasons, such as a desire for equality, appeared to transcend the contextual framing of the vignettes and may therefore have been context-free.

In the research described in this article, the five payoff alternatives in each vignette maintained the specified relationships to each other, each alternative maximizing one and only one social value orientation (Van Lange, 1999), but the cardinal values of the payoffs differed slightly from one vignette to the next. The different payoffs in the team-preference outcomes varied from 50 units for self and 70 units for other to 72 units for self and 103 units for other, with a difference of around 20 or 30 units in each case. Nonetheless, it appears from the overwhelming choices of the team-preference alternatives in the two team-preference vignettes that framing the problem in terms of teamwork led participants to interpret the vignettes in terms of social welfare functions, as predicted by theory (e.g., Bacharach, 1999, 2006), and this type of interpretation was largely absent in the other vignettes. Whether such preferences would be maintained with different team-preference outcomes, including those with highly unequal payoffs, is a problem worth pursuing in future research. Furthermore, the qualitative responses in the current study indicated that participants considered individual levels of payoff ("best for both" reasons) only in the altruistic vignettes. However, it may be that individual levels of payoff remain irrelevant if they are fairly similar, whereas if they are very unequal they may become relevant to outcome preference. Further research is also required to confirm that collective preferences can be engaged in multi-person strategic decisions.

At this stage, looking at outcome preferences across the dimensions used in the study, it is not possible to distinguish empirically between a preference for maximizing the joint utility of individuals and a preference for the best outcome for the group, as a single agent. However, both of these motives depart from the standard assumption of individual payoff maximization in decision theory and game theory. In the present study, the reasons that participants gave for their responses help to clarify their interpretations of the vignettes, and they showed a clear shift of 
focus, in the two team-preference vignettes, from individual payoffs to the payoff for the group as a whole. If it were possible to design an experiment with two different payoff currencies, one a "team currency" and the other an "individual currency," then it might be possible to disentangle the motive to maximize sum of individual desires (i.e., a social welfare outcome) from a motive to maximize the payoff of the group considered as a single entity (i.e., a teampreference outcome).

It is also important to distinguish between collective preferences and actual team reasoning, including the characteristic choice behavior that is integral to full team reasoning. The crucial difference is that team reasoning requires collective preferences and also a characteristic manner of reasoning from preferences to choices. In Bacharach's $(1999,2006)$ stochastic model of team reasoning, expectations about how the other players will act also determine whether an individual engages in team reasoning. Players are likely to engage in team reasoning, including the appropriate choice behavior, only if they assign sufficiently high probability to their coplayers team reasoning also. Investigation of team-reasoning choice behavior, in contrast to collective preferences, requires a different experimental set-up and special challenges of experimental design (Colman, Pulford, \& Rose, in press).

The decision contexts in which team reasoning is most likely to occur are still largely a matter of conjecture. In the research reported in this article, the vignettes that were designed to engage collective preferences were based on the common-sense assumption that such preferences would be most likely to occur in situations in which payoffs go into a common pool and the players benefit jointly from the cooperative outcome, but other factors may also play a part in encouraging collective preferences and reasoning. First, collective preferences and team reasoning may be more likely to arise in situations in which outcomes are perceived to be important rather than trivial, and in which individual decisions are publicly identifiable rather than private, giving salience to social responsibility and accountability. Second, research into cooperation in social dilemmas has indicated that players are more cooperative when their perceived personal efficacy is high (Kerr, 1992), and this factor may also be relevant to collective preferences. Third, and perhaps most important, Dawes, van de Kragt, and Orbell $(1988,1990)$ have shown that almost any manipulation that increases group identity or solidarity radically increases cooperation, independent of expectations of reciprocity, reputational consequences, feelings of conscience, or any other incidental sources of utility often associated with group identity, although group identity may also encourage collective preferences. These findings are relevant and suggestive, but dedicated research designs are needed to establish what specific factors facilitate or inhibit collective preferences and team-reasoning choice behavior.

\section{REFERENCES}

ANDREONI, J. (1990) Impure altruism and donations to public goods: a theory of warm-glow giving. Economic Journal, 100, 464-477.

BACHARACH, M. (1994) Variable universe games. In K. Binmore, A. P. Kirman, \& P. Tani (Eds.), Frontiers of game theory. Cambridge, MA: MIT Press. Pp. 255-275.

BACHARACH, M. (1999) Interactive team reasoning: a contribution to the theory of cooperation. Research in Economics, 53, 117-147.

BACHARACH, M. (2006) Beyond individual choice: teams and frames in game theory (N. Gold, \& R. Sugden, Eds.) Princeton, NJ: Princeton Univ. Press.

BATSON, C. D. (1994) Why act for the public good? Four answers. Personality and Social Psychology Bulletin, 20, 603-610. 
BECKER, G. S. (1974) A theory of social interactions. Journal of Political Economy, 82, 10631093.

BELL, D. E., RAIFFA, H., \& TVERSKY, A. (1988) Descriptive, normative, and prescriptive interactions in decision making. In D. E. Bell, H. Raiffa, \& A. Tversky (Eds.), Decision making: descriptive, normative, and prescriptive interactions. Cambridge, UK: Cambridge Univ. Press. Pp. 9-30.

CIALDINI, R. B., SCHALLER, M., HOULIHAN, D., ARPS, K., FULTZ, J., \& BEAMAN, A. L. (1987) Empathy-based helping: is it selflessly or selfishly motivated? Journal of Personality and Social Psychology, 52, 749-758.

COLMAN, A. M., PULFORD, B. D., \& ROSE, J. (in press) Collective rationality in interactive decisions: Evidence for team reasoning. Acta Psychologica.

DAWES, R. M. (1988) Rational choice in an uncertain world. New York: Harcourt Brace Jovanovich.

DAWES, R. M., VAN DE KRAGT, A. J. C., \& ORBELL, J. M. (1988) Not me or thee but we: the importance of group identity in eliciting cooperation in dilemma situations: Experimental manipulation. Acta Psychologigica, 68, 83-97.

DAWES, R. M., VAN DE KRAGT, A. J. C., \& ORBELL, J. M. (1990) Cooperation for the benefit of us: not me, or my conscience. In J. J. Mansbridge (Ed.), Beyond self-interest. Chicago, IL: University of Chicago Press. Pp. 97-110.

EISER, J. R., \& BHAVNANI, K. K. (1974) The effect of situational meaning on the behaviour of subjects in the Prisoner's Dilemma Game. European Journal of Social Psychology, 4, 9397.

FONTAINE, G. (2004) Sense of presence and self-reported performance in international teams. Psychological Reports, 95, 154-158.

FORESTER, G. L., THOMS, P., \& PINTO, J. K. (2007) Importance of goal setting in virtual project teams. Psychological Reports, 100, 270-274.

GILBERT, M. (1989) Folk psychology takes sociality seriously. Behavioral and Brain Sciences, 12, 707-708.

GILBERT, M. (1994) Me, you, and us: distinguishing "egoism," "altruism," and "groupism." Behavioral and Brain Sciences, 17, 621-622.

GILBERT, M. (2000) Collective preferences, obligations, and rational choice. Economics and Philosophy, 17, 109-119.

HURLEY, S. (1989) Natural reasons. New York: Oxford Univ. Press.

HURLEY, S. (1991) Newcomb's problem, prisoners' dilemma, and collective action. Synthese, 86, 173-196.

HURLEY, S. (1994) A new take from Nozick on Newcomb's problem and prisoners' dilemma. Analysis, 54, 65-72.

JEFFREY, R. C. (1983) The logic of decision (2nd ed.) Chicago, IL: Univ. Chicago Press.

KAHNEMAN, D., \& TVERSKY, A. (1984) Choices, values, and frames. American Psychologist, 39, 341-350.

KAHNEMAN, D., \& TVERSKY, A. (Eds.) (2000) Choices, values, and frames. Cambridge, UK: Cambridge Univ. Press.

KERR, N. L. (1992) Efficacy as a causal and moderating variable in social dilemmas. In W. B. G. Liebrand, D. M. Messick, \& H. A. M. Wilke (Eds.), Social dilemmas: theoretical issues and research findings. Oxford, UK: Pergamon. Pp. 59-80. 
LEVIN, I. P., \& GAETH, G. J. (1988) How consumers are affected by the framing of attribute information before and after consuming the product. Journal of Consumer Research, 15, 374-378.

MANKTELOW, K. I., \& OVER, D. E. (1991) Social roles and utilities in reasoning with deontic conditionals. Cognition, 39, 85-105.

MCCLINTOCK, C. G. (1972) Social motivation: a set of propositions. Behavioral Science, 17, 438-454.

MILES, J. A. (2000) Relationships of collective orientation and cohesion to team outcomes. Psychological Reports, 86, 435-444.

OLSON, M. (1965) The logic of collective action. Cambridge, MA: Harvard Univ. Press.

ORMEROD, T. C., MANKTELOW, K. I., ROBSON, E. H., \& STEWARD, A. P. (1986) Content and representation effects with reasoning tasks in PROLOG form. Behaviour and Information Technology, 5, 157-168.

SAVAGE, L. J. (1972) The foundations of statistics. New York: Dover. (Original work published 1954)

SUGDEN, R. (1993) Thinking as a team: towards an explanation of nonselfish behaviour. Social Philosophy and Policy, 10, 69-89.

SUGDEN, R. (2000) Team preferences. Economics and Philosophy, 16, 175-204.

SUGDEN, R. (2005) The logic of team reasoning. In N. Gold (Ed.), Teamwork: multidisciplinary perspectives. Basingstoke: Palgrave Macmillan. Pp. 181-199.

TVERSKY, A., \& KAHNEMAN, D. (1981) The framing of decisions and the psychology of choice. Science, 211, 453-458.

VAN LANGE, P. A. M. (1999) The pursuit of joint outcomes and equality in outcomes: an integrative model of social value orientation. Journal of Personality and Social Psychology, 77, 337-349.

VON NEUMANN, J., \& MORGENSTERN, O. (1947). The theory of games and economic behavior (2nd ed.). Princeton, NJ: Princeton University Press. 